\title{
SUBCAPSULAR LIVER HEMATOMA - A COMPLICATION AFTER LAPAROSCOPIC CHOLECISTECTOMY
}

\author{
Adriana Tudorache ${ }^{1}$, M. Bica ${ }^{1,2}$, Larisa Săndulescu $^{2,3}$, M. Lazăr ${ }^{2}$ \\ ${ }^{1}$ General Surgery Department, Emergency County Hospital of Craiova \\ ${ }^{2}$ University of Medicine and Pharmacy of Craiova \\ ${ }^{3}$ Research Center of Gastroenterology and Hepatology, Craiova, Romania
}

$\begin{array}{r}\hline \text { CASE } \\ \text { REPORT } \\ \hline\end{array}$

DOI: 10.33695/rojes.v2i1.23

Accepted: 02.12.2020

\begin{abstract}
Subcapsular liver haematoma is among the most severe complications after laparoscopic cholecystectomy, but occurs rarely. The hematoma is usually located around the right lobe of the liver (in $75 \%$ of patients). We report the case of a 71 year old patient who underwent laparoscopic cholecystectomy for acute cholecistitis. Initial postoperative evolution was favorable. On postoperative day 3 patient presents intense abdominal pain and decreased hemoglobin. The CT shows subcapsular hepatic hematoma. Emergency surgery is performed for signs of hemorrhagic shock with evacuation of the hematoma and hemostasis. Postoperative evolution is good. There are several theories proposed for the occurrence of a subcapsular hematoma of the liver after laparoscopic cholecystectomy. Among these, the presence of a hemangioma, the use of NSAIDs or low molecular weight heparin. No clear mechanism is known and the only clinical sign can be abdominal pain. This case reminds us that we must take abdominal pain seriously after cholecystectomy in order to identify severe complications that can occur, such as hepatic subcapsular hematoma.
\end{abstract}

Corresponding author:

Marius Bica Keywords: subcapsular liver hematoma, laparoscopic mariusbk@yahoo.com

\section{Introduction}

Cholecystectomy has remained the most common treatment for symptomatic gallstones. First cholecystectomy was performed in the second half of the 19th century by classic method [1],[2]. In time, surgical procedures have changed and the complications changed in consequence. Nowadays, the standard approach is laparoscopy, first introduced in Germany in 1985. First studies comparing laparoscopic and open procedures were made in 1991 by
Southern Surgeons Club, which showed a smaller number of surgical complications, as well as reduced mortality during laparoscopic surgery [3]. In case of laparoscopic cholecystectomy, the most common complications occurring during peri or early postoperative period include: lesions of the bile duct, bleeding, bile duct leakage, lesions of the intestine, perforation of the gallbladder and choledocholithiasis [4-9]. Subcapsular liver hematoma is among the most severe complications, but occurs rarely. A subcapsular hematoma of the liver is an 
accumulation of blood between Glisson's capsule and the liver parenchyma; rupture into the peritoneum has a $75 \%$ mortality rate. The hematoma is usually located around the right lobe of the liver (in $75 \%$ of patients) [10],[11].

\section{Case report}

A 71 year old female patient, previously untreated, underwent emergency laparoscopic surgery for symptomatic cholelithiasis with suspicion of choledocho-lithiasis. The indication was laparoscopic cholecystectomy with subsequent ERCP if CBD lithiasis was confirmed. Pneumoperitoneum was created using a Veress needle. When we inserted the optical port, we found gangrenous cholecystitis with localized biliary peritonitis. We performed, with difficulty, bipolar cholecystectomy. The CBD was slightly dilated thus cystic duct drainage was performed. Initial evolution was favorable. 72 $\mathrm{h}$ after surgery the patient presented intense abdominal pain, with tachycardia and normal blood pressure. Laboratory tests showed a decrease in the level of hemoglobin from 12.08 to $10.77 \mathrm{~g} \%$. The abdominal pain was resolved with analgesic and antiinflammatory drugs. Two days later the patient continued to have intense pain thus we performed a CT scan that showed subcapsular hepatic hematoma of $8.9 / 4.3 \mathrm{~cm}$, right lobe liver laceration in segment 6- subcapsular hilum of $3 / 2.2 \mathrm{~cm}$ and intrahepatic hematoma segment 7 of $5.2 \mathrm{~cm}$ (Figures 1- 6).

She received blood transfusion, but the decrease of hemoglobin from 8.4 to $6.2 \mathrm{~g} \%$ in the same day together with signs of hemorrhagic shock, were the reason for which emergency laparotomy was decided. Intraoperative, minimally ruptured subcapsular hematoma was diagnosed, involving the right lobe of the liver, without bleeding from the gallbladder site or cystic stump. There was a small amount of blood in the peritoneal cavity. The decision was to evacuate the hematoma, hemostasis and liver packing (Figure 7,8).

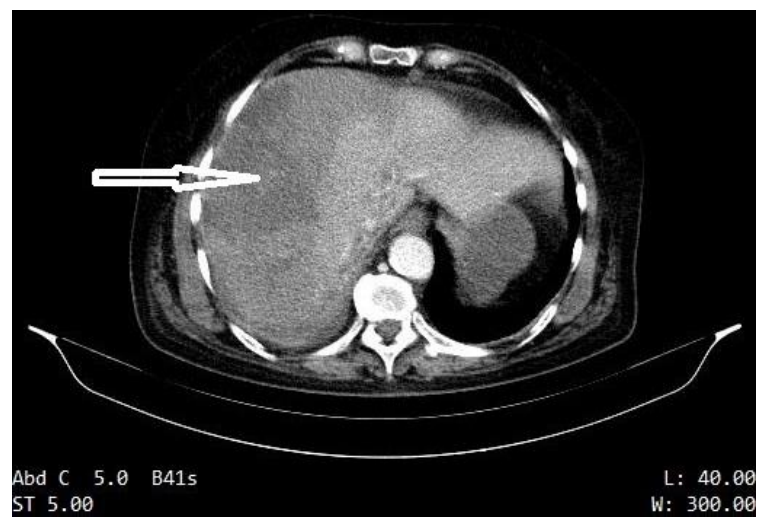

Figure 1 - Right lobe liver laceration in segment 6

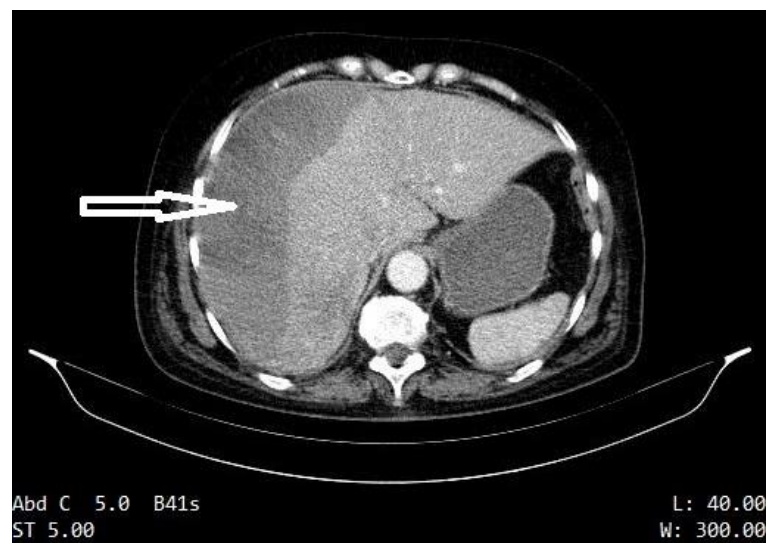

Figure 2 - Subcapsular hepatic hematoma

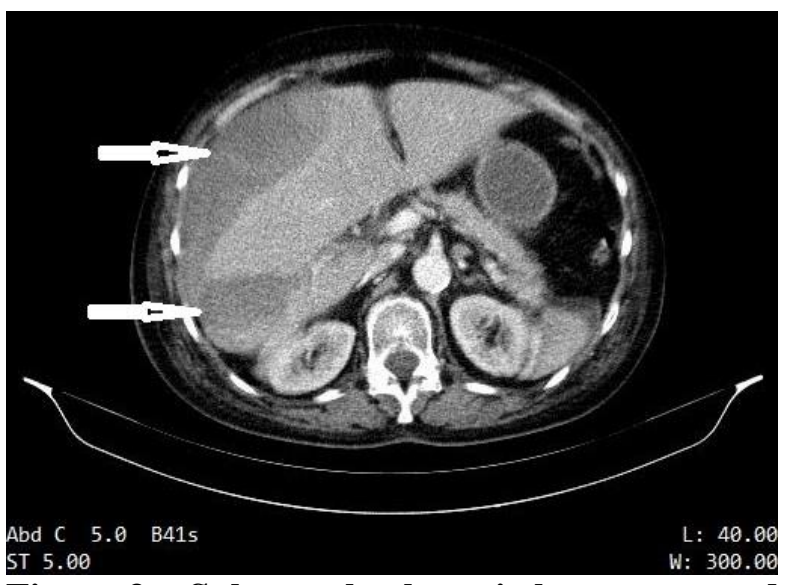

Figure 3 - Subcapsular hepatic hematoma and intrahepatic hematoma towards the hepatic hilum 


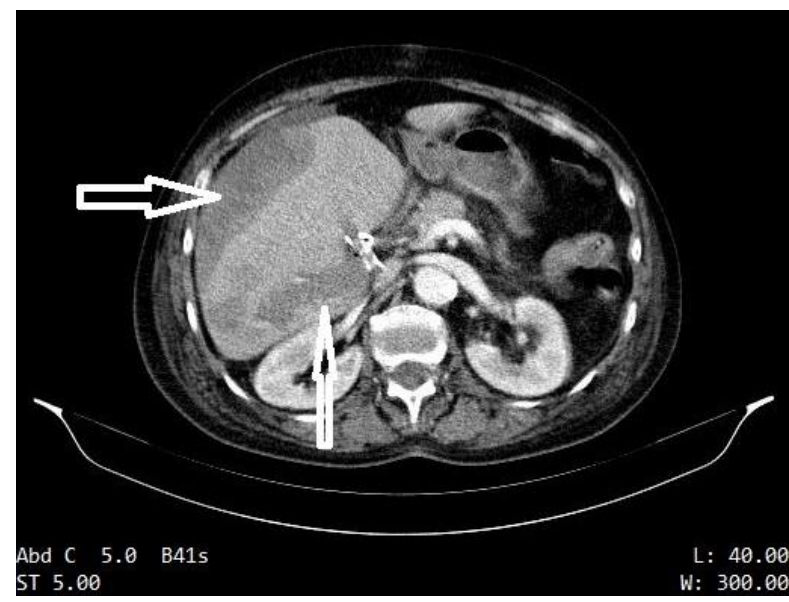

Figure 4 - Subcapsular hepatic hematoma and intrahepatic hematoma towards the hepatic hilum

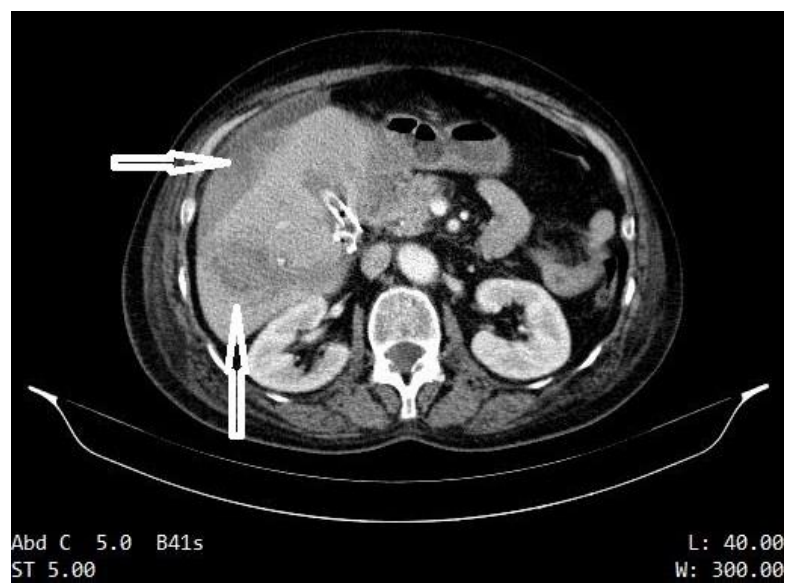

Figure 5 - Subcapsular hepatic hematoma and intrahepatic hematoma towards the hepatic hilum

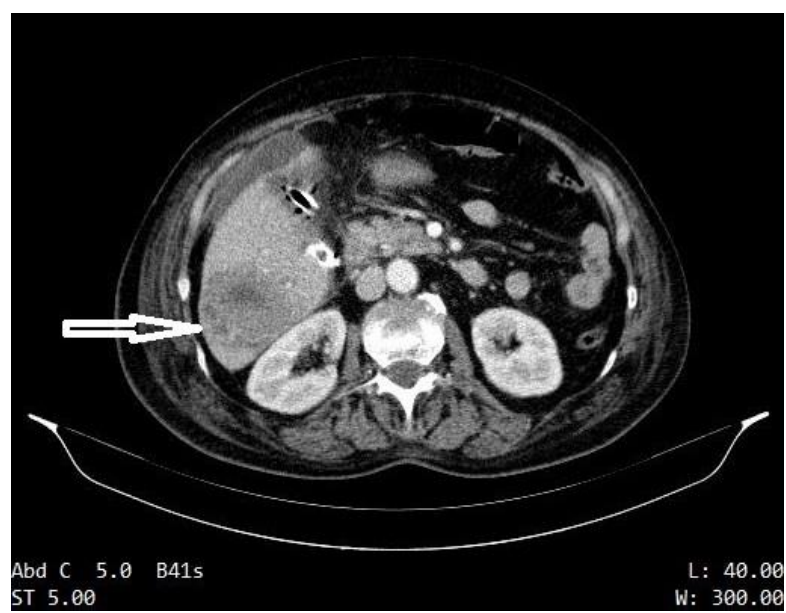

Figure 6 - Intrahepatic hematoma segment 7

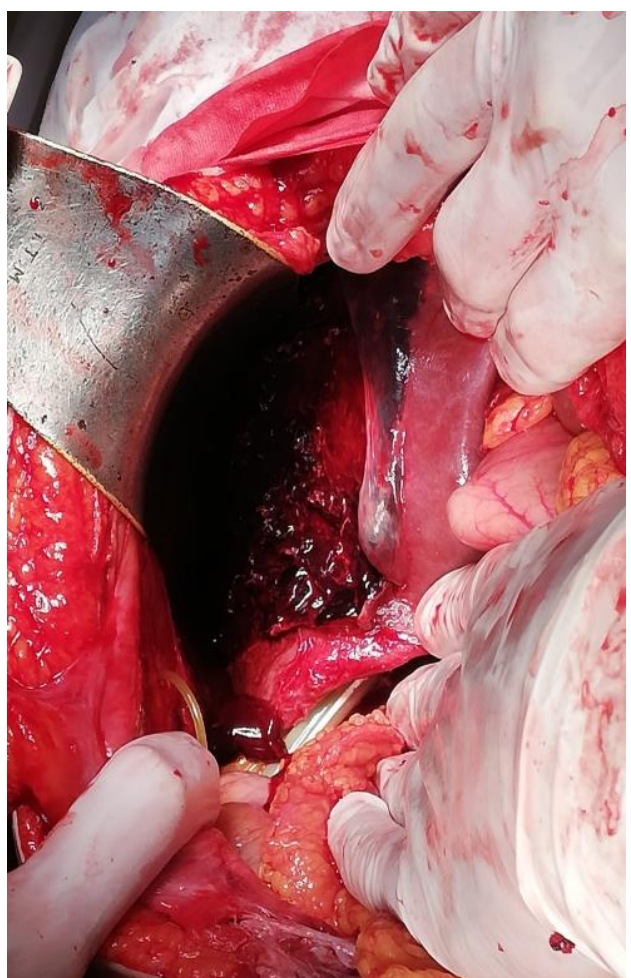

Figure 7 - Intraoperative aspect: ruptured and partially evacuated subcapsular hepatic hematoma

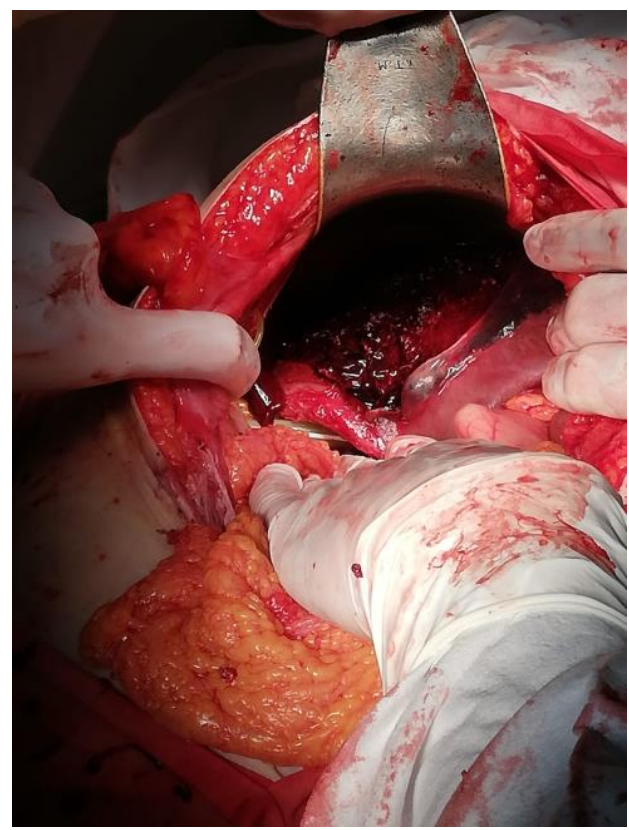

Figure 8 - Intraoperative aspect: ruptured and partially evacuated subcapsular hepatic hematoma 
Packing was removed after 72 hours. On palpation of the liver, the intraparenchimatous hematoma could not be identified (Figures 9, 10).

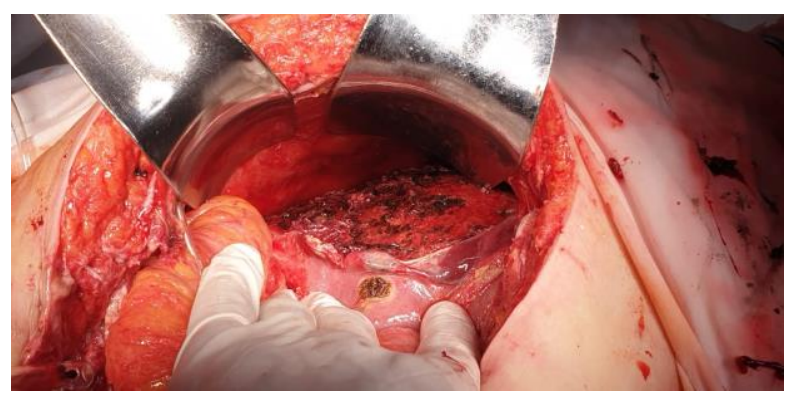

Figure $9-$ Intraoperative aspect at reintervention - no significant bleeding after packing removal

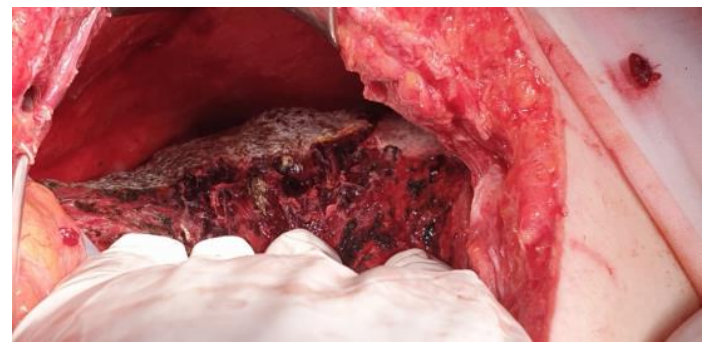

Figure 10 - Intraoperative aspect at reintervention - complete hemostasis achieved with fibrin hemostatic patch

The postoperative evolution was favorable. The CT scan at two weeks post surgery still showed the images of intrahepatic hematoma and laceration in 6th segment (Figures 11, 12, 13, 14).

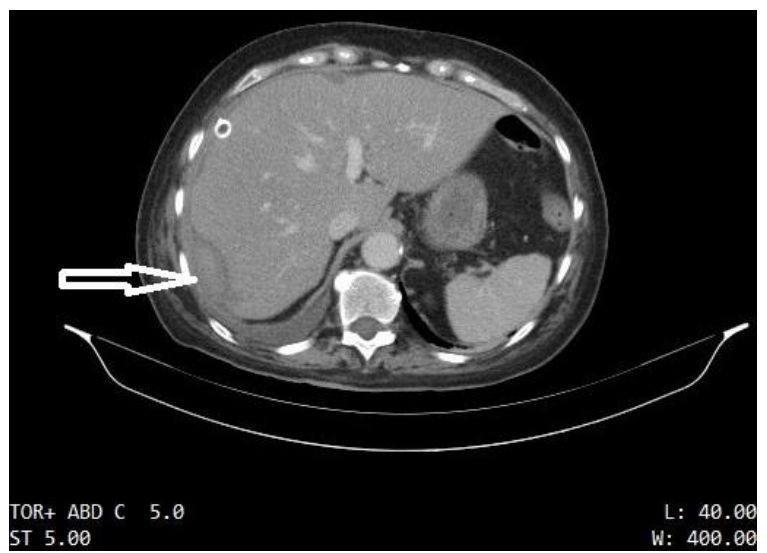

Figure 11 - Minimal residual subcapsular hepatic hematoma

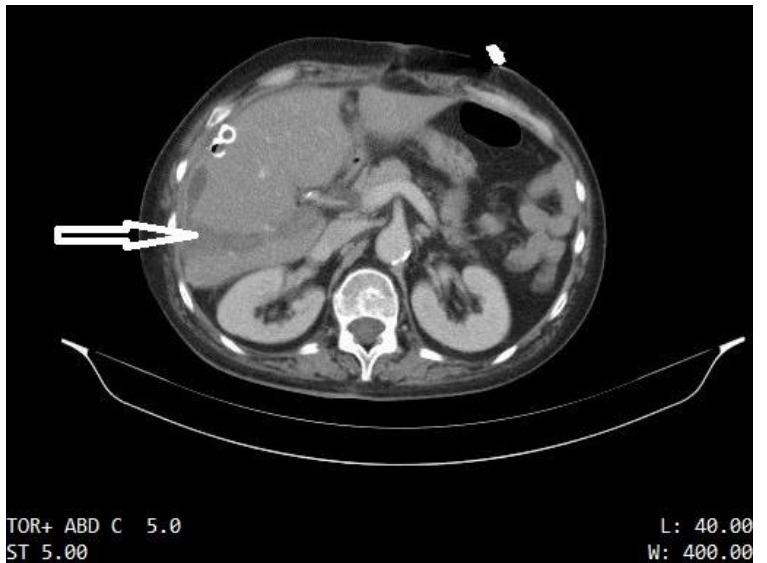

Figure 12 - Intrahepatic hematoma towards the hepatic hilum

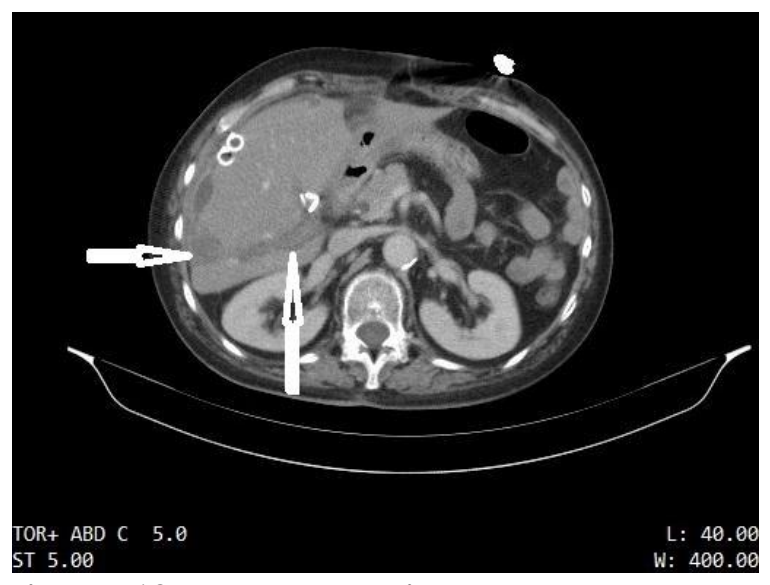

Figure 13 - Intrahepatic hematoma towards the hepatic hilum

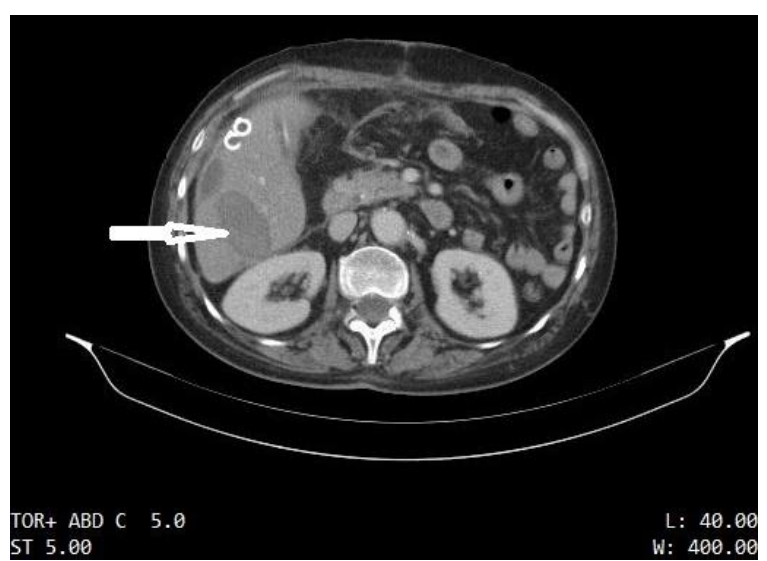

Figure 14 - Intrahepatic hematoma segment 6

Same aspect was seen on abdominal ultrasound (Figure 15, 16, 17). 


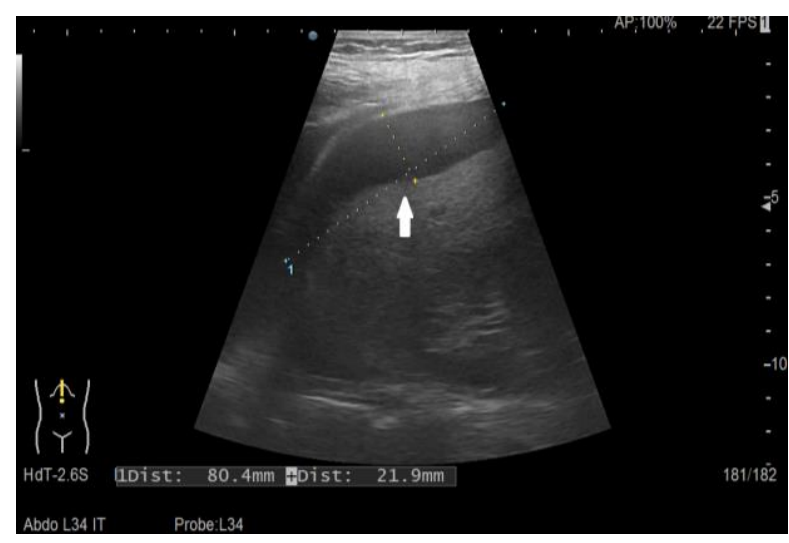

Figure $15 \quad-\quad$ Interhepatodiaphragmatic hematoma

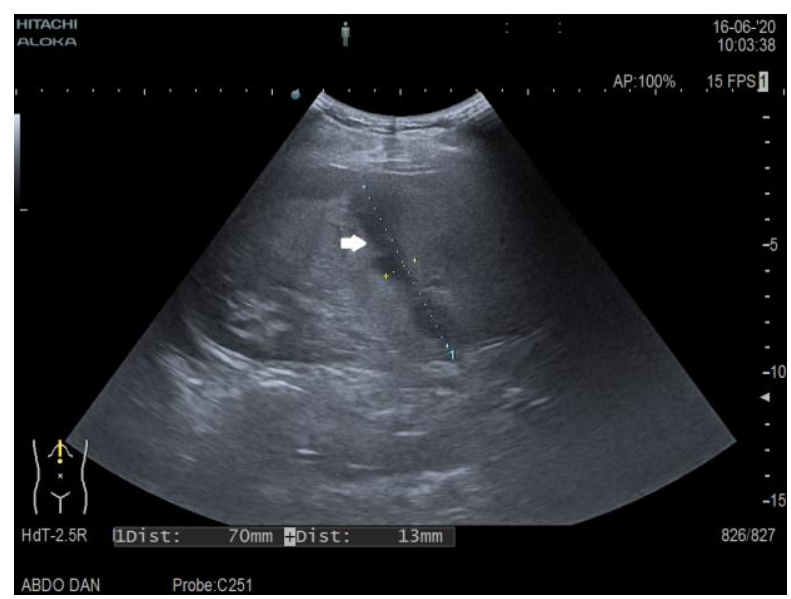

Figure 16 - Intrahepatic hematoma towards the hepatic hillum

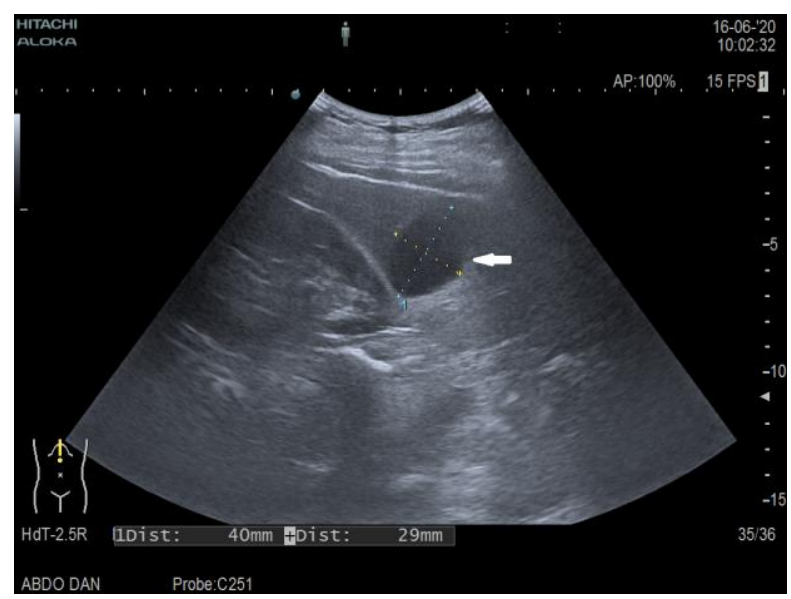

Figure 17 - Hematoma segment 6

The patient did not develop fever, chills or leukocytosis and was discharged on the 32nd postoperative day after tube cholangiography revealed no CBD lithiasis. On follow up, at two weeks after discharge, the ultrasound showed further improvement, with partial resorption of the hematomas and favorable evolution of the patient (Figures 18, 19, 20).

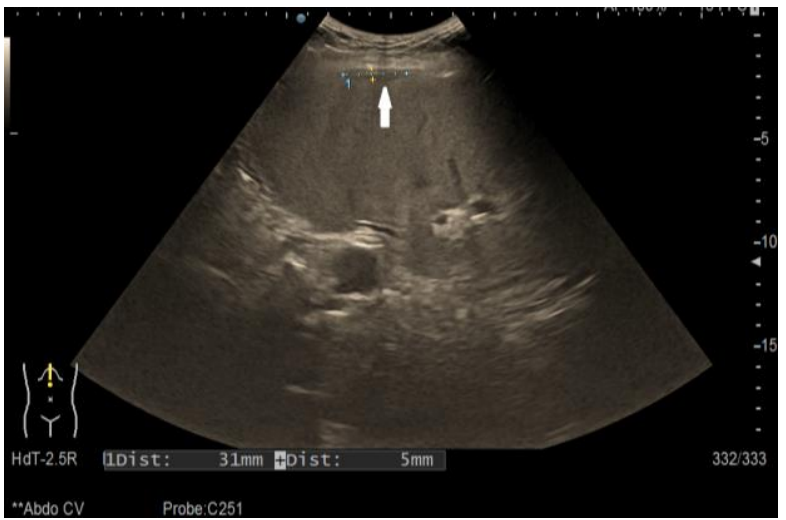

Figure $18 \quad-\quad$ Interhepato-diaphragmatic hematoma

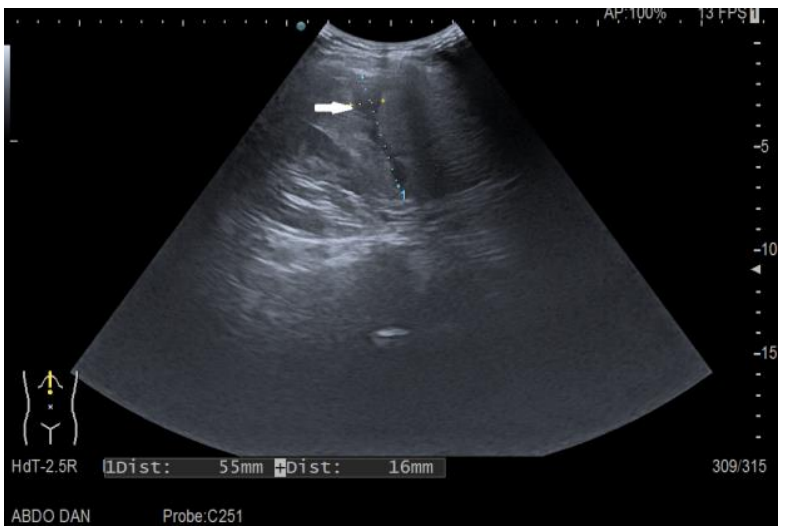

Figure 19 - Intrahepatic hematoma towards the hepatic hilum

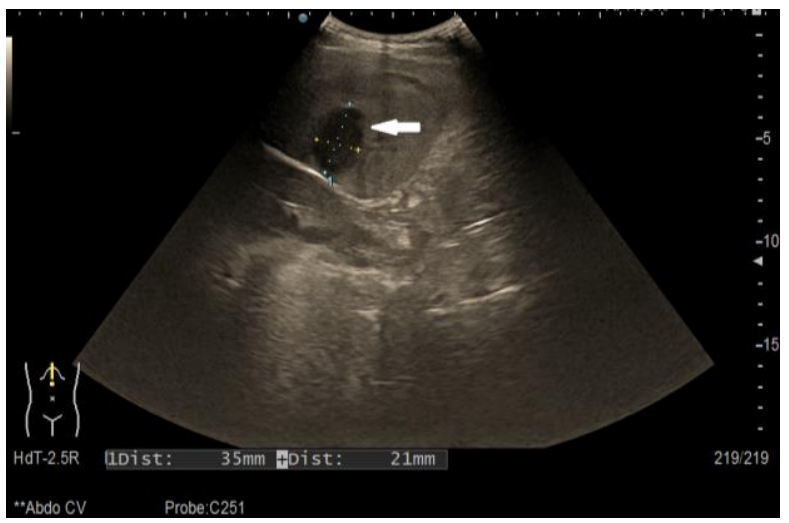

Figure 20 - Hematoma segment 6 
Further follow up is required with ultrasound examination every two weeks and CT scan at 3 months.

\section{Discussion}

Laparoscopic cholecystectomy is the method of choice in acute cholecystitis, considered as safe as the open approach [12]. The most common complications are hemorrhage, biliary peritonitis, common bile duct lesions, residual lithasis. Severe complications occur in approximately $2.6 \%$ of cases [15]. Postoperative hemorrhage is rare $(0.08-2 \%)$ [10],[14] and is due to the gallbladder site, trocar insertion, cystic artery, falciform ligament and rupture of the liver capsule [13].

Hepatic subcapsular hematoma is rare and it is a severe complication of laparoscopic cholecystectomy that may occur within the first days after the procedure.

In our case, the patient presented diffuse abdominal pain, tachycardia and decreased hemoglobin levels. Ultrasound evaluation and CT confirmed the diagnosis of subcapsular hematoma. Similar cases have been reported in patients with hepatic subcapsular hematoma after laparoscopic cholecystectomy. Patients may also show signs of bleeding if the capsule ruptures with massive hemoperitoneum. Also, the hematoma can be infected by bacterial translocation, with patients showing fever, abdominal pain and signs of sepsis [16], and ultrasound evaluation or CT can diagnose the infected hematoma.

In our case, the probable cause of the hematoma is the retraction of a cystic branch into the hepatic parenchyma with intrahepatic hematoma that dissected the parenchyma and then was located under the Glisson's capsule (hepatic laceration would explain this mechanism). This may be due to incorrect manipulation of the gallbladder or intraoperative liver lesions and defective hemostasis.
As other causes of hepatic subcapsular hematoma after cholecystectomy, the presence of a hemangioma has also been described, which during the manipulation of the liver can tear, thus producing the subcapsular hematoma. In our case, no hemangioma was found intraoperative and also, preoperative ultrasound and MRI did not show the presence of a hemangioma.

Another possible cause could be the administration of non-steroidal antiinflammatory drugs such as Ketorolac [10], [18],[19] together with a low molecular weight heparin. This has been associated with a number of cases admitted for postoperative pain.

Also a possible cause could be the insertion of the trocar [17], the excessive traction of the gallbladder which causes the injury of the liver capsule and the excessive manipulation of the liver during the dissection of the gallbladder.

The treatment of hepatic subcapsular hematoma depends on the patient's condition, the size of the hematoma and the value of the hemoglobin. In our case, the patient showing signs of hemorrhagic shock, with progressive decrease of hemoglobin, and CT examination that revealed the hematoma, emergency surgery was decided. If the patient's condition allows, conservative treatment can be attempted, its resorption could be expected in the case of a small hematoma. Also ultrasound-guided percutaneous drainage can resolve the hematoma [11]. In case of hematoma infection, the treatment of choice is percutaneous drainage under CT or ultrasound guidance together with the administration of antibiotic treatment [16], [20]. There are cases cited where the vessel was embolized in active bleeding [16]. There are few articles in literature that describe such a severe complication after laparoscopic cholecystectomy. There is still no universally accepted theory regarding cause, treatment or outcome [21-25]. 


\section{Conclusion}

Few cases of hepatic subcapsular hematoma after laparoscopic cholecystectomy have been described in literature. Hepatic subcapsular hematoma is a very rare but serious complication that endangers the patient's life. This case reminds us that we must not disregard intense abdominal pain after cholecystectomy for it may be the sign of severe complications such as hepatic subcapsular hematoma. Imagistic and biological monitoring in cases of clinical suspicion is extremely important.

\section{References}

[1]Naumowicz E, Białecki J, Kołomecki K. Results of treatment of patients with gallstone disease and ductal calculi by single-stage laparoscopic cholecystectomy and bile duct exploration. Videosurgery Miniinv. 2014;9:179-89.

[2]Bitner M, Jaszewski R, Jander S, Maciejewski M. Laparoscopic cholecystectomy delayed by complicated myocardial infarction with papillary muscle rupture, and performed after unique complex mitral repair. Videosurgery Miniinv. 2013;8:170-3.

[3]The Southern Surgeons Club. A prospective analysis of 1518 laparoscopic cholecystectomies. N Engl J Med. 1991;324:1073-8.

[4]Duca S, Bala O, Al-Hajjar $\mathrm{N}$, et al. Laparoscopic cholecystectomy: incidents and complications. A retrospective analysis of 9542 consecutive laparoscopic operations. HPB. 2003;5:152-8.

[5]Eslami S, Abedini L, Nouri NV, Rabiee M, Samani MK. Bile duct injury outcomes following cholecystectomy: a cross sectional study. Am J Clin Exp Immunol. 2020;9(3):53-57. Published 2020 Jun 15.

[6]Kot M, Głuszek S, Matykiewicz J, Kotucha B. Laparoscopic cholecystectomy is it a safe operation method? Our experiences. Videosurgery Miniinv. 2006;1:113-20.

[7]Mohammadhosseini B, Shirani S. Intraabdominal and abdominal wall haematoma from $5 \mathrm{~mm}$ port insertion site in laparoscopic cholecystectomy. Videosurgery Miniinv. 2011;6:164-6.

[8]Duszewski M, Szewczyk T, Mandryka Y, Modzelewski B. Rare haemorrhagic complications of laparoscopic cholecystectomy. Videosurgery Miniinv. 2009;4:131-4.

[9]Bierca J, Kowalski B, Kosim A, Zmora J. Lethal, iatrogenic complications of laparoscopic cholecystectomy. Videosurgery Miniinv. 2006;1:10-2

[10]Liu QF, Bian LL, Sun MQ, et al. A rare intrahepatic subcapsular hematoma (ISH) after laparoscopic cholecystectomy: a case report and literature review. BMC Surg. 2019;19(1):3. Published 2019 Jan 7. doi:10.1186/s12893-018-0453-9

[11]Minaya Bravo AM, González González E, Ortíz Aguilar M, Larrañaga Barrera E. Two rare cases of intrahepatic subcapsular hematoma after laparoscopic cholecystectomy. Indian J Surg 2010; 72: 481-4.

[12]Navez B, Mutter D, Russier Y, Vix M, Jamali F, Lipski D, et al. Safety of laparoscopic approach for acute cholecystitis: retrospective study of 609 cases. World J Surg. $\quad 2001 ; 25(10): 1352-1356 . \quad$ doi: 10.1007/s00268-001-0122-4.

[13]Briggs CD, Irving GB, Mann CD, Cresswell A, Englert L, Peterson M, et al. . Introduction of a day-case laparoscopic cholecystectomy service in the UK: a critical analysis of factors influencing same-day discharge and contact with primary care providers. Ann R Coll Surg Engl 2009; 91: 583-90.

[14]Shea JA, Healey MJ, Berlin JA, Clarke JR, Malet PF, Staroscik RN, et al. . Mortality and complications associated with laparoscopic cholecystectomy. A metaanalysis. Ann Surg 1996; 224: 609-20. 
[15]Strasberg SM, Hertl M, Soper NJ.. An analysis of the problem of biliary injury during laparoscopic cholecystectomy. J Am Coll Surg 1995; 180: 101-25

[16]de Castro SM, Reekers JA, Dwars BJ.. Delayed intrahepatic subcapsular hematoma after laparoscopic cholecystectomy. Clin Imaging 2012; 36: 629-31

[17]Corsale I, Francioli N., Rigutini M, Aloise F, Adriano Mori P, Buccianelli E. Intrahepatic subcapsular hematoma complicating laparoscopic cholecystectomy. Case report and literature review. Chirurgia 2014; : 39-41.

[18]Erstad BL, Rappaport WD.. Subcapsular hematoma after laparoscopic cholecystectomy, associated with ketorolac administration. Pharmacotherapy 1994; 14: 613-5.

[19]Vuilleumier H, Halkic N.. Ruptured subcapsular hematoma after laparoscopic cholecystectomy attributed to ketorolacinduced coagulopathy. Surg Endosc 2003; 17: 659.

[20]Bhandarkar DS, Katara AN, Shah RS. Intrahepatic subcapsular hematoma complicating laparoscopic cholecystectomy. Surg Endosc 2004; 18: 868-70.

[21]Shibuya K, Midorikawa Y, Mushiake H, Watanabe M, Yamakawa T, Sugiyama Y.
Ruptured hepatic subcapsular hematoma following laparoscopic cholecystectomy: report of a case. Biosci Trends. 2010;4(6):355-358.

[22]Brown V, Martin J, Magee D. A rare case of subcapsular liver haematoma following laparoscopic cholecystectomy. BMJ Case Rep. 2015;2015:bcr2015209800. Published 2015 Jun 25. doi:10.1136/bcr-2015-209800 [23]Moloney BM, Hennessy N, O Malley E, Orefuwa F, McCarthy PA, Collins CG. Subcapsular haematoma following laparoscopic cholecystectomy. BJR Case Rep. 2016;3(2):20160118. Published 2016 Dec 23. doi:10.1259/bjrcr.20160118

[24]Okumus M, Ezberci F, Kuzhan N, Pircanoglu EM, Bozkurt S. A rare cause of dyspnea in a patient presenting to the emergency department: a case report and review of the literature of laparoscopic cholecystectomy complication. J Clin Med Res. 2011;3(5):262-264.

doi:10.4021/jocmr664w

[25]Hansen AJ, Augenstein J, Ong ES. Large subcapsular liver hematoma following singleincision Laparoscopic cholecystectomy. JSLS.2011;15(1):114-116. doi:10.4293/108680811X13022985131615 